\title{
Extravascular Extracellular Volume Fraction
}

National Cancer Institute

\section{Source}

National Cancer Institute. Extravascular Extracellular Volume Fraction. NCI Thesaurus.

Code C132332.

The ratio of interstitial fluid volume to total body fluid. 